\title{
Reidenbach and Robin's Multidimensional Ethics Scale: Testing a Second-Order Factor Model
}

\author{
Howard Buchan \\ State University of New York, Oneonta, USA
}

\begin{abstract}
The purpose of this study is to expand our understanding of the psychometric properties of Reidenbach and Robin's (1988; 1990) MES (multidimensional ethics scale). Unlike earlier investigations that assessed the factor structure of the MES, this study proposes and tests a second-order factor model. Professionals from five public accounting firms participated in this study by completing the 10-item version of the MES. The proposed structure was evaluated using a structural modeling technique, partial least squares. Tests of reliability, validity and internal consistency support four first-order factors and a second-order factor.
\end{abstract}

Keywords: moral sensitivity, MES (multidimensional ethics scale), PLS (partial least squares), public accountants' ethics, second-order factor model.

\section{Introduction}

Reidenbach and Robin $(1988 ; 1990)$ proposed, tested, and refined the MES (multidimensional ethics scale). Originally developed to consider the complexity of the ethical reasoning process in the marketing domain, the MES has been tested in other areas (e.g., accounting — Cohen, Pant, and Sharp, 1993, 1995a, 1995b, 1996, 2001; Cruz, Shafer, and Strawser, 2000; Flory, Phillips, Reidenbach, and Robin, 1992; project management—Loo, 2000, 2001, 2004; tourism-Fennell and Malloy, 1999). General support for a three or four factor model has evolved. The MES, as originally proposed, was based on five normative ethical philosophies and included 33 items. However, current studies provide support for more parsimonious short versions which include eight or 10 items.

Most recently, Loo (2004) has evaluated the psychometric properties of the eight-item scale using project management dilemmas. Results support three dimensions: moral equity, relativism, and contractualism. Loo (2004) suggests that the scale total can be used as a general measure of ethics. Cohen et al. (1996) also propose a relationship between the MES and Rest's (1986) four component model. For example, they suggest factor scores arguably relate to the first component, moral sensitivity.

The purpose of this study is to extend the work of Loo (2004) and Cohen et al. (1996) in two important ways. To date, the psychometric properties of the scale have been tested assuming a single factor model. This paper proposes and tests the psychometric properties of a second-order factor model. Second, the model will be tested using PLS (partial least squares), a structural equation method that offers certain advantages to those engaged in ethics research. The second section of this paper develops the theoretical justification for a 
second-order factor model. The third section outlines the research methods and the fourth section discusses the data analysis and results. Conclusions are set forth in the final section.

\section{Background and Development of Second-Order Factor Model}

\section{Development of MES}

Philosophical dimensions used to evaluate responses to ethical dilemmas have long been of interest to those engaged in marketing ethics research. Hunt and Vitell's (1986) general theory of marketing ethics was based on the broad theories of deontology and teleology. The model assumes that individuals use both types of philosophical reasoning when making ethical judgments. The model also recognizes that there may be loose coupling between judgment, intention, and behavior because of situational constraints, etc..

Reidenbach and Robin (1988) acknowledged the efforts in this area, but argued that the focus on deontological and teleological philosophies was too restrictive. Thus, they developed a 29-item MES that incorporated the five moral philosophies: egoism, utilitarianism, relativism, justice, and deontology. Egoism and utilitarianism can be viewed as subcategories of teleology and justice a subcategory of deontology. The primary empirical question was whether individuals utilize a consistent pattern of reasoning across situations. The initial study and factor analysis produced mixed results and the authors encouraged further investigation.

Reidenbach and Robin (1990) used confirmatory factor analysis to further refine and validate the MES. The original scale was reduced to eight items representing three dimensions: moral equity, relativism, and contractualism. The following describes the five underlying moral philosophies that provide the framework for the MES.

The cognitive moral development literature and the theories espoused by Lawrence Kohlberg (1969) and James Rest $(1986$; 1979) rely heavily on the philosophy of justice which deals with equal and fair treatment. Relativism supports the notion that an act can be judged only in terms of a specific culture; in other words, there are no universal truths. Egoism deals with the consequences of a specific action; if the act promotes long-term self-interest, it is considered ethical. Utilitarianism also looks to the consequences of the act to judge its ethicality. The action resulting in the greatest good considering all parties is the most ethical. Finally, deontology is often referred to as the rules based philosophy. Consequences are not the focus of the evaluation of the ethicality of an act. Rather, judgment is based on the action itself regardless of outcome.

As mentioned, three factors emerged from the confirmatory factor analysis (1990). First, the moral equity dimension included the justice scale items as well as one item originally thought to tap relativism ("acceptable/unacceptable to my family") and one from the deontological scale ("morally/not morally right"). Second, the relativism dimension included the remaining scale items in that category ("traditionally acceptable/unacceptable" and "culturally acceptable/unacceptable"). The authors point out that these particular items relate more to cultural systems than individual considerations. Third, the contractual dimension was wholly deontological and included scale items such as: "violates/does not violate unspoken promises", and "violates/does not violate an unwritten contract".

The MES used by Reidenbach and Robin (1990) included three short scenarios; each described an ethical dilemma and the action taken. Subjects were asked to evaluate the action (for example "just/unjust", "fair/unfair") on a seven-point scale. Each dichotomy relates to one of the dimensions described above. Subjects were also asked to indicate the probability that they would commit the same act (a measure of intent) and whether they considered the act to be ethical (a measure of ethical judgment). 
The MES has been further tested in general business ethics research. For example, Schwepker and Ingram (1996) found a positive relationship between moral judgment and job performance of salespeople. Similar to other marketing studies, LaTour, Snipes, and Bliss (1996) considered only the moral equity and relativism dimensions when measuring the perceived ethicality of advertisements. Using principal components factor analysis, they found support for only one general factor.

Most recently, Loo (2004) examined the psychometric properties of the eight-item version of the MES which excludes the utilitarianism and egoism dimensions. Vignettes were developed by the authors and considered the various phases of project management. Results support the three factors; however, the authors suggest that the total scale score can be used as a general measure of ethics. Like Reidenbach and Robin (1990), they suggest that the version of the scale used should relate to the nature of the ethical dilemma(s).

\section{Use of MES-Accounting Ethics Research}

As Reidenbach and Robin (1990) correctly point out:

Psychometric measures more realistically evolve rather than burst forth full bloom and complete... It seems plausible that the dimensions could maintain their validity across a wide variety of business applications, but this requires continued testing. If the measures are independent of context, then the diversity of potential application expands greatly. (pp. 649-650)

In this regard, it is also useful to test the performance in different industries. Cohen, Pant, and Sharp (1993; 1995a; 1995b; 1996; 2001) have been the most active in cultivating a line of research in the accounting domain, primarily in an international context. To test the generalization of the MES beyond marketing to accounting, Cohen et al. (1993) replicated and extended the scale development studies of Reidenbach and Robin (1988; 1990). The authors expanded the scale to include four new items; two representing the egoism dimension and two representing the utilitarianism dimension. Notably, one scenario deals with an accounting dilemma. Moreover, to better test the probability that subjects would perform such an act, the authors added a question to help determine whether the "halo" effect was influencing the results of the study. Findings support the relativism and justice factors, but unlike Reidenbach and Robin (1990), the authors found accountants also used utilitarian reasoning. This seems somewhat intuitive as cost $v$. benefit analysis is used extensively in the accounting domain. No support was found for the egoism dimension.

Cohen et al. (1996) argue that the MES is related to Rest's four-component model, suggesting that the raw MES factor scores are related to the first component, moral sensitivity. Furthermore, they demonstrate how they can be used to measure the importance of the action which they argue is a component of step 2, making the moral judgment. To test ethical awareness and orientation, the MES was completed (using eight short vignettes and a 12-item scale) by 127 (60\% response rate) Canadian auditors representing 13 offices of a "Big 6" accounting firm. Once again, factor analysis supported utilitarian reasoning as an important dimension.

Cruz et al. (2000) considered the factors that influence ethical judgments of tax practitioners. Similar to other accounting studies, the authors found support for four dimensions (moral equity, contractualism, relativism, and utilitarianism). Results suggest that the relative importance of ethical dimensions remains somewhat consistent across cases. Moral equity explained the greatest percentage of the variance. The relationship between philosophies and ethical judgments was evaluated by regressing practitioners' ethical judgments on the mean responses to the MES dimensions. Adjusted R2 is ranged from 0.66 to 0.89 . Moral equity was statistically significant in all three dilemma cases and contractualism was significant in 2 out of 3 cases. The authors also found that behavioral intentions are most heavily influenced by the moral equity 
dimension, followed by contractualism.

As discussed, the raw factor scores may be considered a measure of moral sensitivity. Empirical evidence to date suggests accountants may show relatively consistent patterns of reasoning across situations typically encountered in public practice. Thus, the MES may provide an appropriate measure of moral sensitivity.

\section{Second-Order Factor Model}

The foregoing discussion of MES focused on studies that investigated the reliability and validity of the scale originally proposed by Reidenbach and Robin (1988). However, of interest in this study is the difference between a group-factor model and a second-order factor model. Generally, prior studies using the MES are consistent with a group-factor model (Rindskopf \& Rose, 1988). In other words, each ethical philosophy represents a factor which is associated with observed variables (indicators) which are linear combinations of the appropriate factor and unique variable. This first-order factor model is presented in Figure 1.

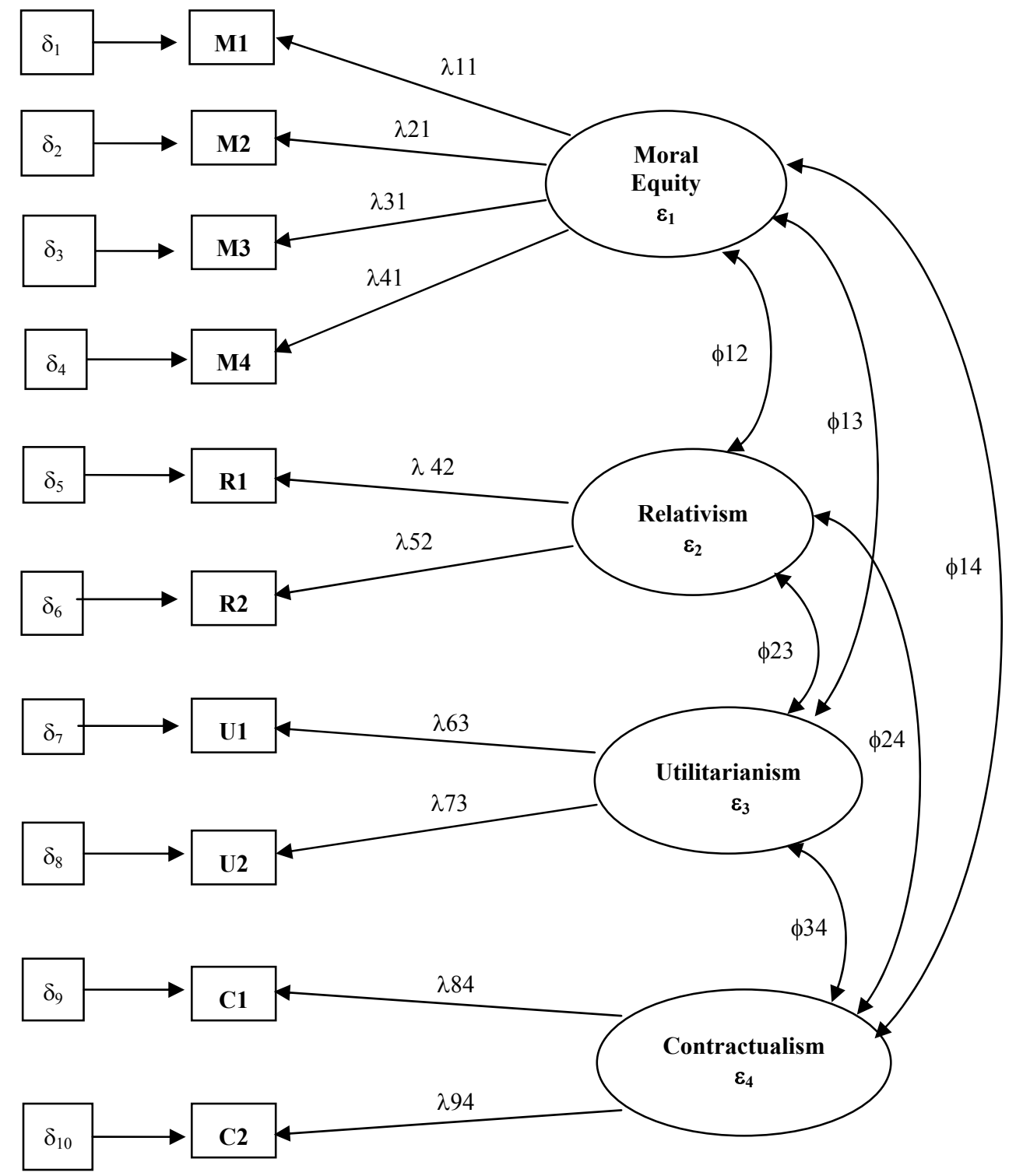

Figure 1. First-order factor model. 
A first-order factor model means that all MES items are highly correlated with each other and the various scales (moral equity, relativism, etc.) are correlated and measure the same underlying construct. In contrast, in a second-order factor model, the scales are associated with distinguishable dimensions of the general factor. Thus, variance is shared because of the higher-order factor, yet each retains variance unique to the lower-order factor (Hull, Tedlie, \& Lehn, 1995). The latent variables (philosophical dimensions) are not directly connected to scale items.

The one-factor model is considered more restrictive than the group factor model. Figure 2 illustrates how the second-order factor model can be considered a special case of the group factor model. In other words, placing restrictions (a structure) on the correlations shown in the group factor model changes it into the second-order factor model (thus, representing a nested model). As Rindskopf and Rose (1988) note, data consistent with a particular model will also be consistent with a less restricted model. Choice among models (which fit the data) can be based on "theoretical plausibility, parsimony or a statistical test of the differences".

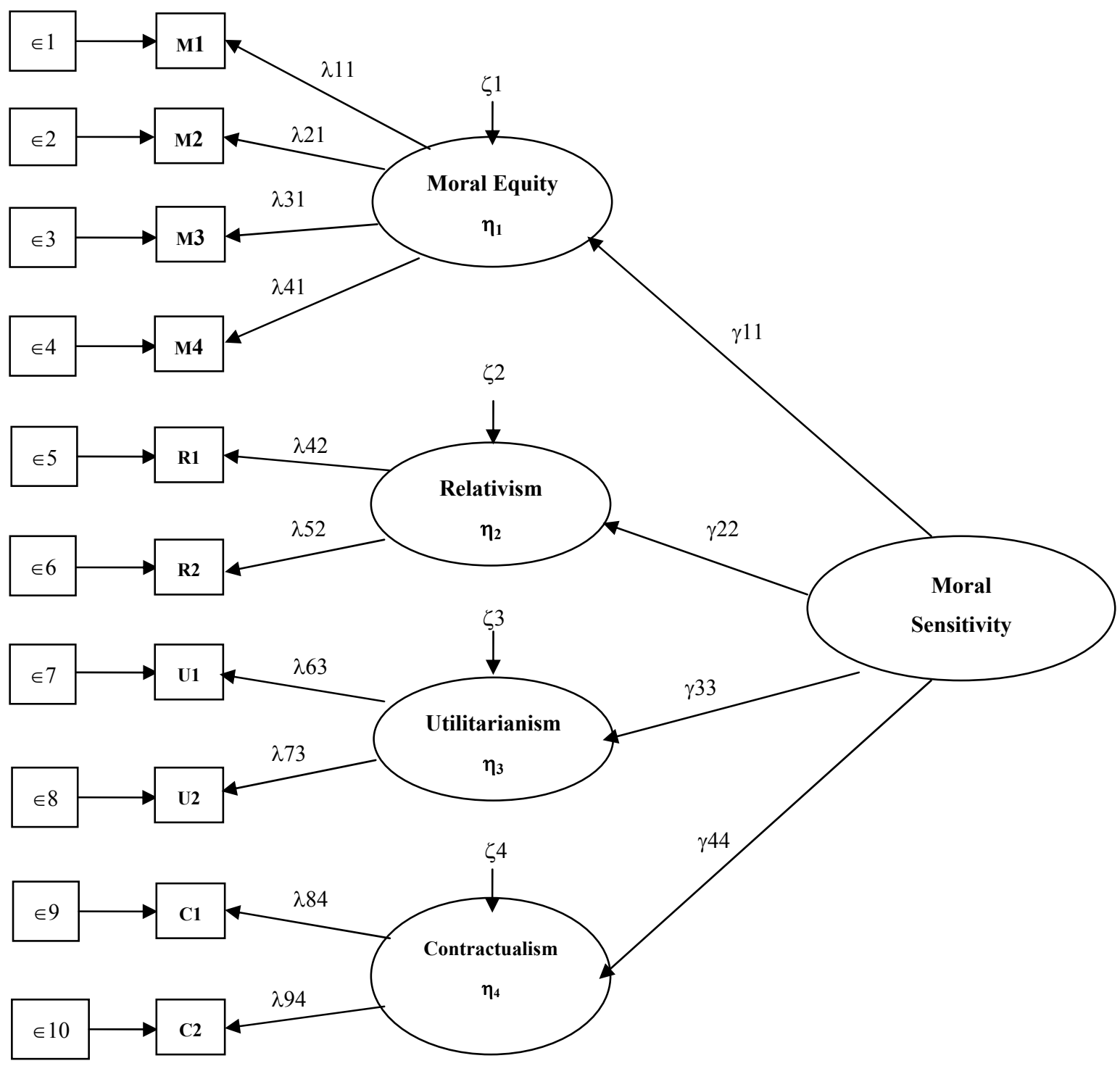

Figure 2. Hypothesized second-order factor model of moral sensitivity. 
Chin and Gopal (1995) suggest that this approach assumes that an underlying overall latent construct (e.g., moral sensitivity) exists and each philosophical dimension reflects that second-order latent construct. This also means, at least with respect to the behaviors of interest, moral sensitivity for a particular subject is represented by one combination of moral philosophies.

Generally, a change in one of the first-order factors would result in a corresponding change in the other factors that reflect the higher-order factor. Theoretical underpinnings and empirical results help guide the analysis in this regard. For example, Reidenbach and Robin (1990) point out that "each philosophy enjoys a well recognized and heavily debated tradition. However, while each philosophy has its own unique conceptual core, there does exist a certain conceptual overlap among them" (p. 640). Empirical results also suggest relationships between the dimensions (e.g., Reidenbach \& Robin, 1990; Cruz et al., 2000; Flory et al., 1992).

\section{Method}

\section{Research Design}

This non-experimental cross-sectional study uses a survey questionnaire. The measures have been used in a wide variety of previous research studies and have demonstrated acceptable levels of scale reliability and validity. Human subjects were required and the protocol was approved by the appropriate institutional review board. Data were collected as part of a larger study.

\section{Sample and Procedure}

Five public accounting firms located in the northeast and operating primarily in one state participated in this study. The convenience sample is non-probabilistic; however, the subjects are representative of the domain of interest. The extent of participation and the administration of the survey instrument varied among the firms.

Potential subjects received a letter inviting them to participate in the study. The letter adhered to guidelines established by the human subjects institutional review board, briefly described the study and offered assurance that responses were confidential and anonymity was guaranteed.

\section{Response Rate}

Table 1 summarizes the response rate by firm. A $65.6 \%$ response rate is based on a final sample size of 95 .

Table 1

MES Survey Response Rate

\begin{tabular}{lll}
\hline Firm & Distributed & Usable Responses \\
\hline A & 13 & 13 \\
B & 12 & 12 \\
C & 40 & 19 \\
D & 55 & 33 \\
E & 40 & 18 \\
Total & 160 & 95 \\
\hline
\end{tabular}

\section{Measures}

MES originally developed and extended by Reidenbach and Robin $(1988 ; 1990)$ and further tested in an accounting context by Cohen et al. (1993; 1995a; 1995b; 1996; 2001), Flory et al. (1992) and Cruz et al. (2000) was used. Based on the results of the series of studies in the accounting domain, the 10 item version of the MES 
was used. Two items representing the egoism dimension will not be included because of the lack of empirical support. Thus, the instrument includes the original eight items validated by the work of Reidenbach and Robin (1990), Flory et al. (1992) and Loo (2004), plus the two items representing the utilitarianism dimension (Cohen et al., 1993, 1995a, 1995b, 1996, 2001; Cruz et al., 2000). Studies in the accounting domain suggest the MES items represent valid and reliable measures (e.g., [3] $-\alpha=0.83-0.96$; [23] $-\alpha=0.63-0.8$; [9] $-\alpha=0.75-0.94$; $[8]-\alpha=0.73-0.94)$. PLS will also be used to test the proposed second-order factor structure. Subjects read the background information describing the ethical dilemma (see Appendix 1) and then responded to each of the items measured on a seven-point scale (see Appendix 2).

\section{Social Desirability Bias}

The 10-item version of the 33-item Marlowe-Crowne Social Desirability Scale (Beck \& Ajzen, 1991) which was developed by Strahan and Gerbasi (1960), and tested by Fischer and Fick (1982), was used to test for social desirability response bias. Cronbach's alpha was used to test reliability of the scale and response bias was evaluated based on the degree of correlation between the social desirability scale and the MES.

\section{Analysis}

Sample Characteristics. Table 2 summarizes staffing levels of the subjects participating in the study. Participation by the partners seems to illustrate strong support for the project.

Table 2

Position in the Firm

\begin{tabular}{lcc}
\hline Position & Number & Percent $(\%)$ \\
\hline Staff & 32 & 34 \\
Senior & 14 & 15 \\
Manager/Supervisor & 15 & 16 \\
Senior Manager & 5 & 5 \\
Partner/Principal & 29 & 30 \\
Total & 95 & 100 \\
\hline
\end{tabular}

Table 3 presents the average years of experience by gender. Females represent $47 \%$ of the total respondents; however, the average number of years of experience for females is considerably less than that of males.

Table 3

Gender and Average Years of Experience

\begin{tabular}{llcc}
\hline Gender & Number & Percent $(\%)$ & Years of public accounting experience \\
\hline Female & 45 & 47 & 6.2 \\
Male & 50 & 53 & 13.7 \\
Total & 95 & 100 & \\
\hline
\end{tabular}

\section{Data Analysis Method}

The models were tested using PLS which is a structural modeling technique (SEM) developed by Wold (1993). PLS offers the ability to test the measurement and structural components within the context of one structural equation model. Fornell and Bookstein (1972) point out that PLS avoids the problems of factor indeterminacy and inadmissible solutions. Moreover, PLS does not rely on multivariate normality and independence of observations (Wold, 1985) and combines regression (ordinary least squares), path analysis and 
principal components factor analysis.

The PLS iterative algorithm is variance-based and attempts to find the appropriate indicator weights for each block of construct indicators. Thus, the latent constructs represent the weighted sum of their indicators. Iterations cycle between the structural and measurement components; the algorithm fixes the parameters in one component (i.e., fixed point estimation) while estimating parameters in the other. In the second stage of the iterative process (upon convergence) OLS regression is used to estimate the paths using the latent constructs estimated in the first phase (Fornell \& Bookstein, 1982).

Another advantage of PLS is the relatively small sample size required. One heuristic used to specify minimum sample size requirements is ten times the number of exogenous factors influencing the endogenous latent variable with the largest number of paths (Wold, 1985). In this study, moral sensitivity is the only endogenous construct for the second-order factor model and four paths are proposed. Thus, the minimum sample size is 40 .

Increased use of PLS in a business context is evident (Wold, 1985; Fornell \& Bookstein, 1982; Chin \& Newsted, 1999; Cool, Dierickx, \& Jemison, 1989; House, Spangler, \& Woycke, 1991; Howell \& Higgins, 1990; Johansson \& Yip, 1994). Areas of investigation include marketing, strategy, organizational behavior, management accounting and MIS. PLS offers significant advantages to those engaged in ethics research. However, use of this technique to explore ethical issues in the accounting domain appears limited. Based on the foregoing, PLS was selected for the following reasons. First, it is well suited for the small sample size. Based on the heuristic discussed above, the minimum sample size requirement is satisfied. Second, these data do not have to satisfy the strict distributional requirements of covariance-based SEM techniques such as LISREL.

PLS-Graph (Version 3.0), a graphical user interface software program developed by Chin and Frye (Thompson, Higgins, \& Howel, 1994), was used to implement the PLS technique.

Test of Reliability and Validity: Second-Order Factor Model (Moral Sensitivity). Chin (2004) suggests that the higher-order model should have at least four first-order factors to adequately test convergent validity. Based on the foregoing review of empirical studies, four underlying moral philosophies are posited: moral equity, utilitarian, relativism, and contractualism. Following Chin's (2004) recommendations, convergent validity of the second-order factor model was tested by examining the paths between ethical sensitivity (second-order latent variable) and the first-order factors. Individual items for each construct are designated as reflective (i.e., molecular) which implies that each construct is viewed as an existing entity and that the items reflect the underlying construct. The degree to which an item is considered a good indicator of the latent variable and thereby is an adequate measure evaluated by reviewing the loadings (simple correlations). Fornell and Larcker (PLS-Graph (Version 3.0), 2001) recommend 0.7; however, this is somewhat more conservative than 0.5 often used in factor analysis. The weights are an indication of the contribution of the item in the determination of the composite construct score.

Chin (1998) suggests using the method of repeated indicators. The second order factor (moral sensitivity) is measured by using the indicators for each of the first-order factors (i.e., moral equity, relativism, utilitarianism and contractualism). The overall model was then estimated using the partial least squares algorithm. Table 4 presents the first-order factors, indicator weights and factor loadings. With the exception of one indicator of moral equity, all indicators exceed the 0.7 cut-off.

Table 5 provides further support for the second-order factor model. The paths between moral sensitivity 
and its first order factors are of high magnitude and have significantly high $t$-values. Such parameter estimates can be interpreted as the reliability of observed indicators to constructs. As mentioned above, this structure presents the covariation among first-order factors in a more parsimonious way (Fornell \& Larcker, 1981).

Social Desirability Response Bias. The correlation of the short-version of the Marlowe-Crowne scale with the MES was not significant.

Table 4

Measures of Internal Consistency: The Second Order-Factor Model

\begin{tabular}{lcc}
\hline First order factors \& items & Weights & Factor loadings \\
\hline Moral equity & & \\
M1 & 0.3245 & 0.9630 \\
M2 & 0.3251 & 0.9381 \\
M3 & 0.3176 & 0.9354 \\
M4 & 0.1743 & 0.4902 \\
Relativism & & \\
R1 & -0.5211 & -0.9106 \\
R2 & -0.5679 & -0.9253 \\
Utilitariamism & & \\
U1 & 0.6559 & 0.8582 \\
U2 & 0.5518 & 0.7922 \\
Contractualism & & \\
C1 & 0.6149 & 0.9008 \\
C2 & 0.5199 & 0.8580 \\
\hline
\end{tabular}

Table 5

Loadings of First-Order Factors on Second-Order Factors

\begin{tabular}{lc}
\hline & Factor loadings \\
\hline 1. Moral equity & 0.9347 \\
2. Relativism & -0.7676 \\
3. Utilitarianism & 0.8016 \\
4. Contractualism & 0.8574 \\
\hline
\end{tabular}

\section{Discussion and Conclusion}

An interesting finding was support for the second-order factor model of moral sensitivity in a PLS context. Paths (factor loadings) between the second-order and first-order factors provide some evidence of the relative contribution (importance) of each dimension. Consistent with earlier studies (Cruz et al., 2000; Cohen et al., 1993), moral equity has an important influence on the evaluation.

Another interesting finding relates to the influence of the relativism dimension. Loadings are negative and the smallest in magnitude. Relativism deals with cultural considerations and results may reflect the attitude that those outside of the public accounting environment would not be as troubled by the actions described in the ethical dilemmas.

As Chin (2004) points out, "to postulate the existence of a second-order factor that sits in a vacuum holds little value. Rather, it must be related to other factors in a conceptual model" (p. 3). Future research can consider the relationship of moral sensitivity (the higher-order factor) to other factors hypothesized as having a direct effect on ethical judgments and intentions. 


\section{References}

Beck, L., \& Ajzen, I. (1991). Predicting dishonest actions using the theory of planned behavior. J. Res. Personality, 25, $285-301$.

Chenhall, R. H. (2004). The role of cognitive and affective conflict in early implementation of activity-based management. Behav. Res. in Acc., 16, 19-44.

Chin, W. W. (1998). Issues and opinions on structural equation modeling. MIS Quarterly, 22(March), 7-16.

Chin, W. W. (2000). Partial least squares for researchers: An overview and presentation of recent advances using the PLS approach. ICIS Tutorial and Panel Presentation.

Chin, W., \& Gopal, A. (1995). Adoption intention in GSS: Relative importance of beliefs. Data Base, 23(2\&3), 42-64.

Chin, W. W., \& Newsted, P. R. (1999). Structural equation modeling with small samples using partial least squares. In R. H. Hoyle (Ed.). Statistical strategies for small sample research (pp. 308-337). Thousand Oaks, C.A.: Sage Publications.

Cohen, J., Pant, L., \& Sharp, D. (1993). A validation and extension of a multidimensional ethics scale. J. Bus. Ethics, 12(1), 13-26.

Cohen, J., Pant, L., \& Sharp, D. (1995a). An international comparison of moral constructs underlying auditors' ethical judgments. Res. on Acc. Ethics, 1, 97-126.

Cohen, J., Pant, L., \& Sharp, D. (1995b). An exploratory examination of international differences in auditors' ethical perceptions. Behav. Res. in Acc., 7, 37-64.

Cohen, J., Pant, L., \& Sharp, D. (1996). Measuring the ethical awareness and ethical orientation of Canadian auditors. Behav. Res. in Acc., 8(Supplement), 98-119.

Cohen, J., Pant, L., \& Sharp, D. (1998). The effect of gender and academic discipline diversity on the ethical evaluations, ethical intention and ethical orientation of potential public accounting recruits. Acc. Horizons, 12(3), 250-270.

Cohen, J., Pant, L., \& Sharp, D. (2001). An examination of differences in ethical decision-making between Canadian business students and accounting professionals. J. Bus. Ethics, 30, 319-336.

Cool, K. I., Dierickx, I., \& Jemison, D. (1989). Business strategy, market structure and risk-return relationships: A structural approach. Strat. Manage J., 10(6), 507- 522.

Crowne, D. P., \& Marlowe, D. (1960). A scale of social desirability independent of psychopathology. J. Consult Psychol., 24, 349-354.

Cruz, C., Shafer, W., \& Strawser, J. (2000). A multidimensional analysis of tax practitioner's ethical judgments. J. Bus Ethics, 3, 223-244.

Fennell, D., \& Malloy, D. (1999). Measuring the ethical nature of tourism operators. Annals of Tour Res., 26(4), 928-943.

Fischer, D. G., \& Fick, C. (1993). Measuring social desirability: Short forms of the Marlowe-Crowne social desirability scale. Educ. and Psychol. Meas., 53, 417-425.

Flory, S., Phillips, T. Jr., Reidenbach, R., \& Robin, D. (1992). A multidimensional analysis of selected ethical issues in accounting. The Acc. Review, 67(2), 284-302.

Flynn, L. M. (2001). An empirical investigation of the impact of environment on individual ethical analysis by corporate accountants and human resource managers (Unpublished doctoral dissertation, Binghamton University, Binghamton, NY).

Fornell, C., \& Bookstein, F. L. (1982). Two structural equations models: LISREL and PLS applied to consumer exit-voice theory. J. Market Res., 19, 440-452.

Fornell, C., \& Larcker, D. F. (1981). Evaluating structural equation models with unobservable variables and measurement error. $J$. Market Res., 18, 39-50. PLS-Graph (Version 3.0). (2001). Computer software developed by Chin and Frye, Soft Modeling Inc..

Himmelfarb, S., \& Lickteig, C. (1982). Social desirability and the randomized response technique. J. Pers. and Soc. Psychol., 43, 710-717.

House, R. J., Spangler, W. D., \& Woycke, J. (1991). Personality and charisma in the U.S. presidency: A psychological theory of leader effectiveness. Administrative Science Quarterly, 36(3), 364-396.

Howell, J. M., \& Higgins, C. A. (1990). Champions of technological innovation. Admin Sci. Quart, 35(2), 317-341.

Hull, J., Tedlie, J., \& Lehn, D. (1995). Modeling the relation of personality variables to symptom complaints. The unique role of negative affectivity. In R. H. Hoyle (Ed.). Structural equation modeling, concepts, issues and applications. Thousand Oaks, C.A.: Sage Publications.

Hunt, S., \& Vitell, S. (1986). A general theory of marketing ethics. J. Macromarketing, 6(Spring), 5-16.

Johansson, J. K., \& Yip, G. S. (1994). Exploiting globalization: U.S. and Japanese strategies. Strat Manage J., 15, $579-601$. 
Kohlberg, L. (1969). Stages and sequences: The cognitive developmental approach to socialization. In D. Goslin (Ed.). Handbook of socialization theory and research. Chicago, I.L.: Rand McNally.

LaTour, M., Snipes, R., \& Bliss, S. (1996). Don't be afraid to use fear appeals: An experimental study. J. Adver Res., March/April, 59-67.

Loo, R. (2000). Confirmatory factor analysis of the full and short versions of the Marlowe-Crowne social desirability scale. J. Soc. Psychology, 140(5), 628-635.

Loo, R. (2001). Encouraging classroom discussion of ethical dilemmas in research management: Three vignettes. Teach Bus. Ethics, 5, 195-212.

Loo, R. (2004). Support for Reidenbach and Robin's (1990) eight-item multidimensional ethics scale. The Soc. Sci. Journal, 41, 289-295.

Rest, J. (1979). Development in judging moral issues. Minneapolis, M.N.: University of Minnesota Press.

Rest, J. (1986). Moral development: Advances in research and theory. New York, N.Y.: Praeger.

Reidenbach, R., \& Robin, D. (1988). Some initial steps toward improving the measurement of ethical evaluation of marketing activities. J. Bus. Ethics, 7, 871-879.

Reidenbach, R., \& Robin, D. (1990). Toward the development of a multi-dimensional scale for improving evaluations of business ethics. J. Bus. Ethics, 9, 639-653.

Rindskopf, D., \& Rose, T. (1988). Some theory and application of confirmatory second-order factor analysis. Multivar Behav. Res., 23, 51-67.

Schwepker, Jr. C. H., \& Ingram, T. N. (1996). Improving sales performance through ethics: The relationship between salesperson moral judgment and job performance. J. Bus. Ethics, 15(11), 1151-1160.

Segars, A. H., \& Grover, V. (1998). Strategic information systems and planning success: An investigation of the construct and its measurement. MIS Quarterly(June), 139-163.

Strahan, R., \& Gerbasi, K. L. (1972). Short, homogeneous version of the Marlowe-Crowne social desirability scale. J. Clin. Psychol., 28, 191-193.

Thompson, R. L., Higgins, C. A., \& Howel, J. M. (1994). Influence of experience on personal computer utilization: Testing a conceptual model. J. Manag Info. Sys., 11(1), 167-188.

Wold, H. (1985). Systems analysis by partial least squares. In P. Nijkamp, H. Leitner, N. Wrigley (Eds.). Measuring the unmeasurable (pp. 221-251). Boston, M.A.: Martinus Nijhoff.

\section{Appendix 1 Vignettes}

\section{Vignette 1: Lowballing}

A partner is developing a bid for a new client. The partner deliberately sets the bid significantly below cost. The partner knows that the audit will lose money in the first few years. However, the expectation is that the firm will be able to raise the audit fee a few years down the road to generate a profit.

Action. In response to a question from the prospective client, the partner indicates that fees should not be expected to rise significantly in the foreseeable future.

Adapted from Cohen et al. (1995a; 1995b)

\section{Vignette 2: Charging Personal Expenses to the Firm}

A supervisor, the mother of two small children, has been promoted and assigned to an engagement which requires travel away from home for the firm on a regular basis. Because these trips are frequent and inconvenience her family life, she is contemplating charging some small personal expenses while traveling for the firm. She has heard that this is common practice in the firm.

Action. The supervisor charges the firm $\$ 50$ for family gifts.

Adapted from Cohen et al. (1995b; 1998) and Flynn (2000). 


\section{Appendix 2 MES (Multidimensional Ethics Scale)}

$\begin{array}{ll}\text { M1 } & \text { Just } \\ \text { M2 } & \text { Fair } \\ \text { M3 } & \text { Morally Right } \\ \text { M4 } & \text { Not Acceptable to My Family } \\ \text { R1 } & \text { Culturally Acceptable } \\ \text { R2 } & \text { Traditionally Acceptable } \\ \text { U1 } & \text { Produces the Greatest Utility } \\ \text { U2 } & \text { Minimizes Benefits While Maximizing Harm } \\ \text { C1 } & \text { Does Not Violate an Unwritten Contract } \\ \text { C2 } & \text { Violates an Unspoken Contract }\end{array}$

Source: Adapted from Cruz et al. (2000).

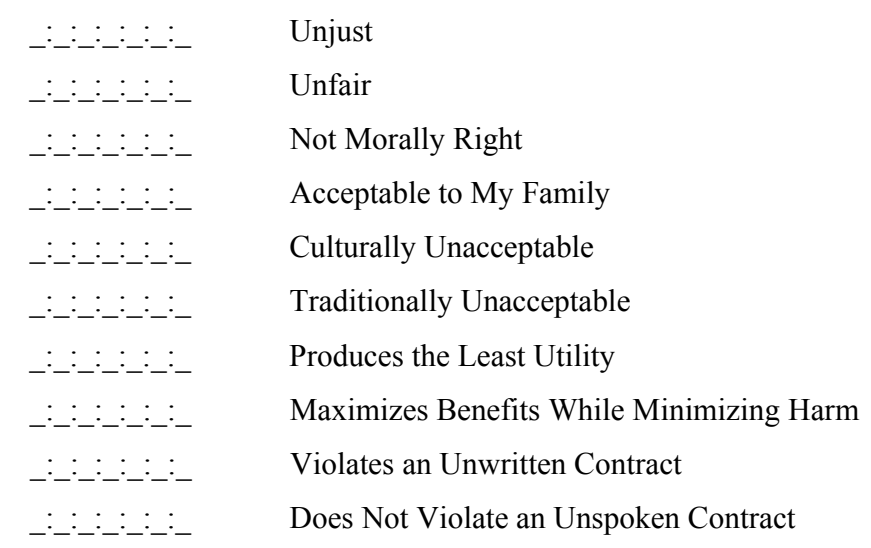

